\title{
Studies on Digitalis. X. Effects of Ouabain on Forearm Vas- cular Resistance and Venous Tone in Normal Sub- jects and in Patients in Heart Failure *
}

\author{
Dean T. Mason and Eugene Braunwald with the technical assistance of \\ Richard B. Karsh and Frederick A. Bullock
}

(From the Cardiology Branch, National Heart Institute, Bethesda, Md.)

Although the therapeutic action of digitalis is generally agreed to result largely from its ability to stimulate the contraction of the myocardium, there has been considerable suspicion that cardiac glycosides may also act directly upon the systemic vascular bed. Excised arterial and venous strips contract when exposed to digitalis glycosides (1-4), and generalized systemic arteriolar and venous constriction has been induced by digitalis in anesthetized open-chest dogs on cardiopulmonary bypass $(5,6)$. In normal human subjects digitalis glycosides elevate arterial pressure and either have little effect on or diminish cardiac output, thus augmenting the calculated systemic vascular resistance (7). More direct evidence that digitalis acts upon vascular smooth muscle was provided by the observation that the drug elevated systemic vascular resistance in patients on total cardiopulmonary bypass, in whom the systemic perfusion rate was held constant, and in whom the cardiac effects of the drug could not influence arterial pressure directly (8). Little information is available, however, concerning the extracardiac actions of digitalis glycosides when given in the usual clinical doses to intact human subjects. The present investigation was undertaken to characterize the effects of ouabain on a specific vascular bed, that of the forearm. The effects of the drug on both the resistance and capacitance vessels were examined in normal subjects and in patients with congestive heart failure.

\section{Materials and Methods}

The effects of ouabain were determined in 12 normal subjects, between 18 and 49 years of age, and in 6 patients with congestive heart failure, between 34 and 52 years in age. Four of these patients had rheumatic mitral

* Submitted for publication August 7, 1963 ; accepted November 21, 1963. valve disease and 2 had coronary artery disease. All 6 of the patients had elevated venous pressures ranging from 15.8 to 23.1 and averaging $19.3 \mathrm{~cm} \mathrm{H}_{2} \mathrm{O}$, measured in a large antecubital vein with a water manometer and a no. 18 needle, utilizing a base line $5 \mathrm{~cm}$ beneath the sternal angle. At right and left heart catheterization all 6 patients had elevated pulmonary arterial and left atrial pressures and cardiac indexes below normal $(2.50 \mathrm{~L}$ per minute per $\mathrm{m}^{2}$ ). At the time of the study none of the patients were being treated with diuretics or salt restriction. However, they voluntarily restricted their activities in the hospital because of symptoms of diminished cardiac reserve. All 6 were in Classes III or IV, according to the functional criteria of the New York Heart Association.

A plethysmographic technique was employed for the measurement of forearm blood flow and the estimation of forearm venous tone. Changes in forearm volume were determined by means of the Whitney mercury-inrubber strain gauge plethysmograph (9) placed on the midforearm. The gauge was mounted so that its maximal tension was less than $10 \mathrm{~g}$, to prevent the gauge from obstructing even the superficial veins beneath it. The close correspondence between changes in volume determined with this device and those measured by the water-filled plethysmograph have been presented in detail by other workers (9-13). The circuit design and method of calibration of the mercury-in-rubber gauges employed were identical to those described by Holling, Boland, and Russ $(13,14)$. Forearm venous pressure was measured with a Statham P23D pressure transducer through a 14$\mathrm{cm}$ PE no. 50 catheter introduced into a large vein at the wrist and advanced so that its tip lay just distal to the mercury-in-rubber gauge. The forearm was elevated to make the venous pressure exactly zero; the importance of this maneuver in studying the pressure-volume relationships of the venous bed has been emphasized by Wood and Eckstein (15).

To eliminate the vessels in the hand from these determinations, a sphygmomanometric cuff $7 \mathrm{~cm}$ wide was placed around the wrist and inflated to a level exceeding systolic arterial pressure just before each venous occlusion. A sphygmomanometric cuff $13 \mathrm{~cm}$ wide was placed around the upper arm, and forearm venous occlusion was produced by suddenly inflating this cuff to a pressure below the diastolic arterial pressure, utilizing a tank of compressed air to provide a constant pressure 
a. .

CONTROL

$0.05-01-33$

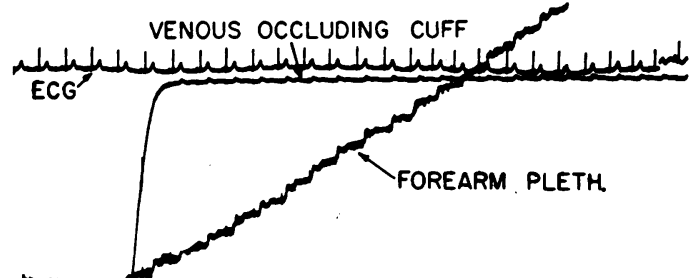

OUABAIN

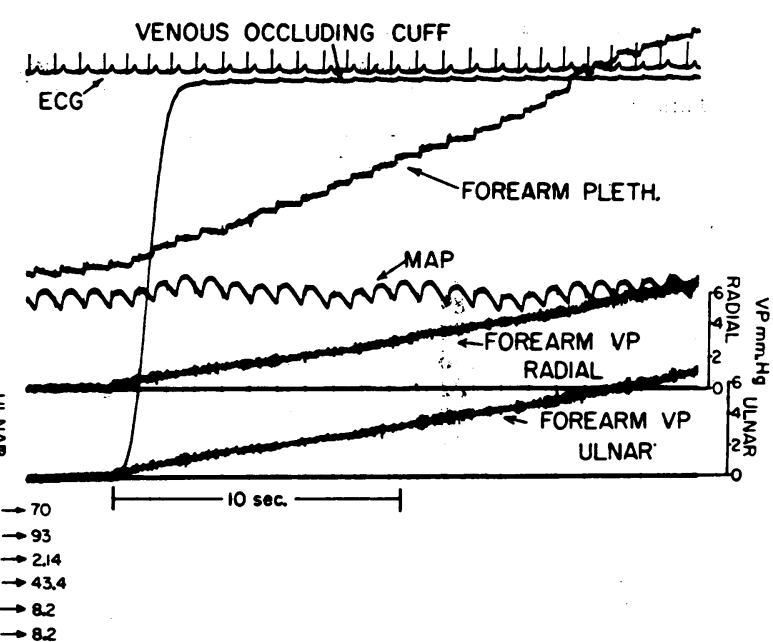

Fig. 1. Two segments of the recording in a nORMal subject. The tracing on the left was obtained during the control period; that on the right was, recorded 40 minutes after the injection of $0.5 \mathrm{mg}$ ouabain. MAP= mean arterial pressure. PLETH refers to the forearm plethysmographic tracing. VP= venous pressure, recorded simultaneously in two veins, one on the radial, the other on the ulnar side of the forearm. The figures below the tracing are the values of the variables that were measured or calculated. $H R=$ heart rate, $B F=$ forearm blood flow, and $F V R=$ forearm vascular resistance. $\mathrm{VT}_{\mathbf{R}}=$ venous tone, calculated using the vein on the radial aspect of the forearm. $\mathrm{VT}_{\mathrm{U}}=$ venous tone, calculated using the vein on the ulnar aspect of the forearm. Note that after ouabain the rise in pressure in both veins is more rapid, while the rise in the plethysmographic tracing is less steep than during the control period.

TABLE I

Changes during a 40-minute control period in 6 normal subjects and 3 patients with heart failure*.

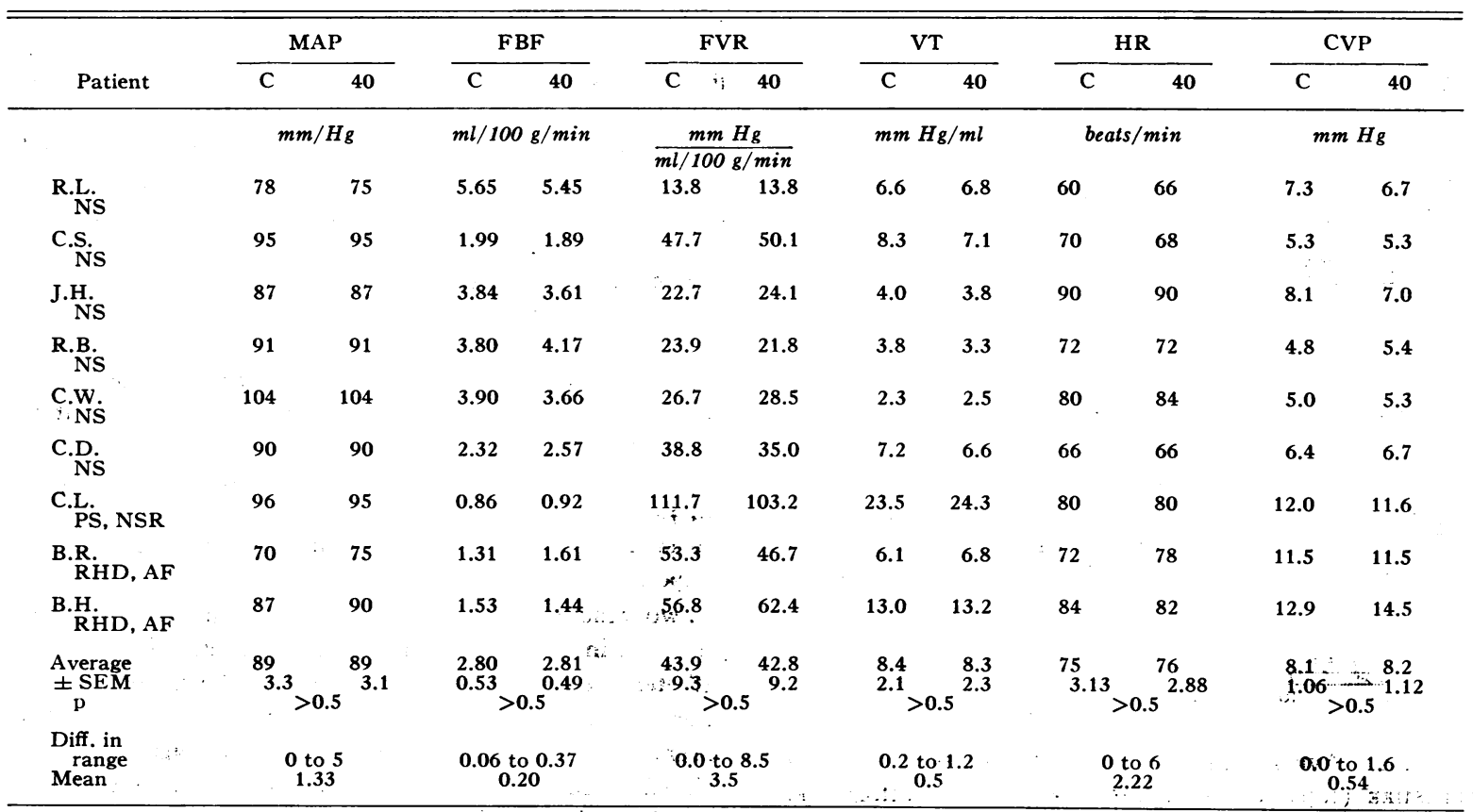

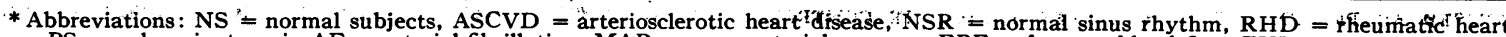
disease, $\mathrm{PS}=$ pulmonic stenosis, AF $=$ arterial fibrillation, MAP = mean arterial pressure, F BF = forearm blood flow, $\mathrm{FVR}=\mathrm{forearm}$ vascular resistance, $\mathrm{VT}=$ venous tone (acute occlusion technique), $\mathrm{HR}=$ heart rate, $\mathrm{CVP}=$ central venous pressure, $\mathrm{C}=$ initial còntrol observations $\mathbf{4 0}=$ observations after a 40 -minute waiting period, SEM $=$ standard error of the mean, and Diff. = difference between initial observations and those made 40 minutes later. The range and mean differences are given regardless of sign. 
TABLE: II

Circulatory effects of ouabain

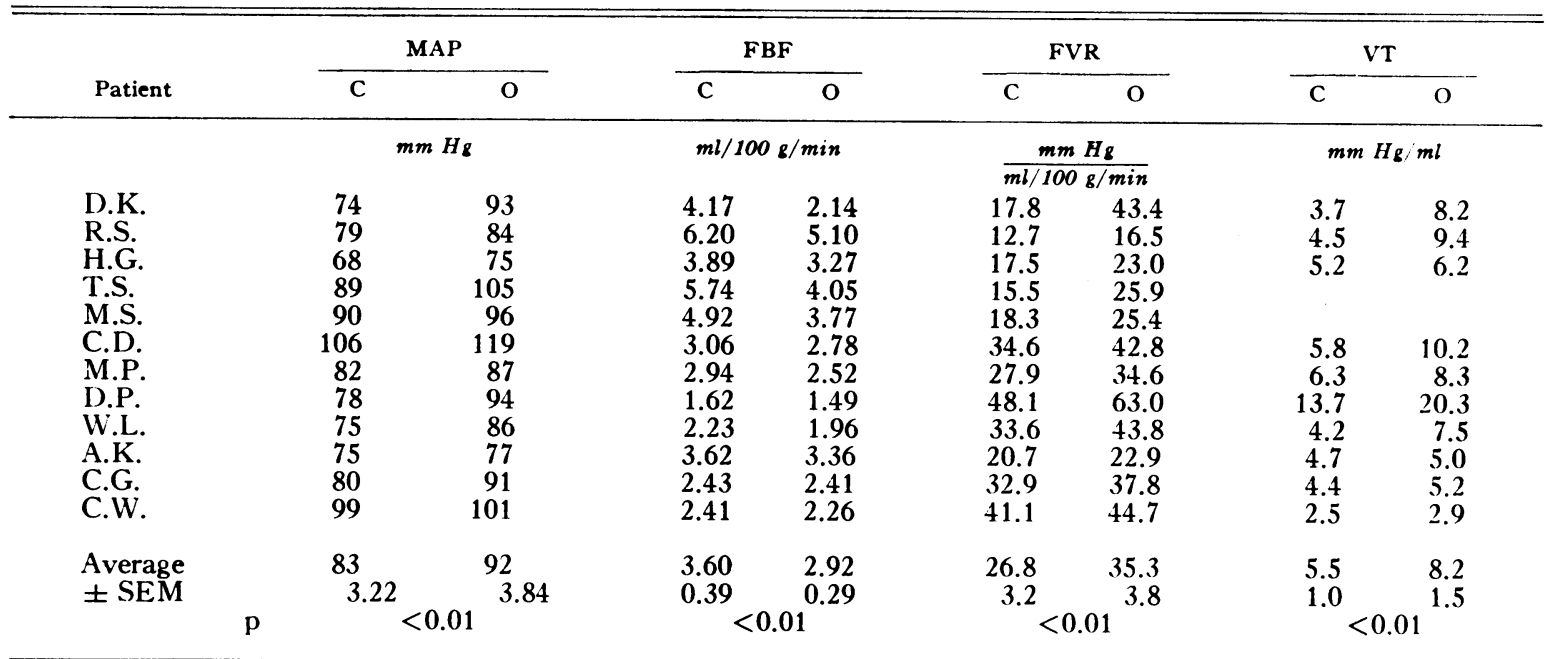

* Abbreviations same as for Table $\mathrm{I}$. $\mathrm{CI}=$ cardiac index, FBF/CO = ratio of forearm blood flow to cardiac output, $\mathrm{SVR}=$ systemic vascular resistance, $\mathrm{O}=$ observations after ouabain. The measurements made 40 minutes after ouabain are given for MAP, FBF, FVR, VT, HR, and CVP. The measurements made 60 minutes af ter ouabain are given
for CI, FBF/CO, and SVR.

source. Arterial pressure was measured with a Statham strain gauge through an indwelling arterial needle placed into the brachial artery of the opposite forearm. All recordings were made on a multichannel photographic recorder.

The heart rate was determined from the electrocardiogram. Forearm blood flow, expressed as $\mathrm{ml}$ per $100 \mathrm{~g}$
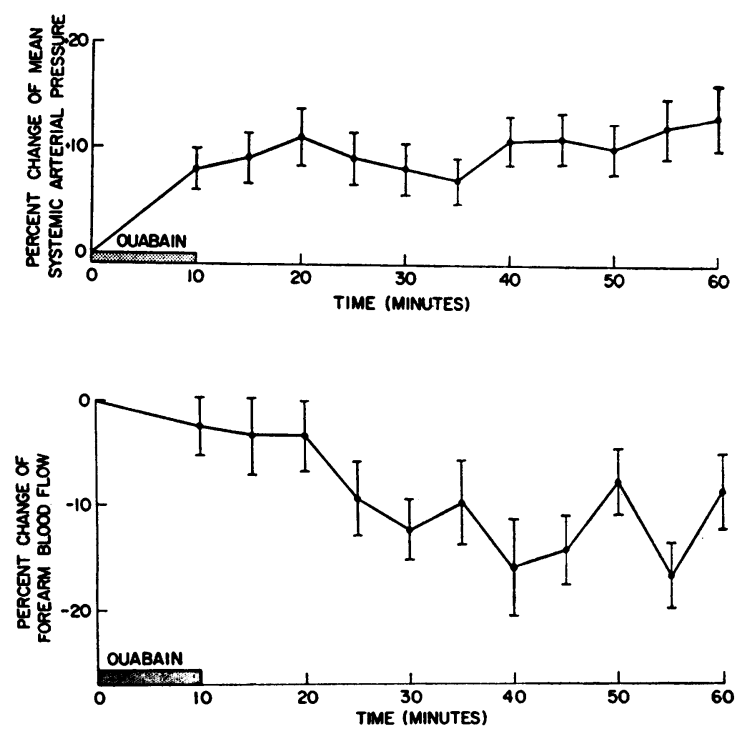

Fig. 2. Average change ( \pm SEM) of mean arterial PRESSURE (top) AND FOREARM BLOOD FLOW (bottom), EXPRESSEd AS PERCENTAGe OF CHANGes From THE CONTROL VALUES IN THE NORMAL SUBJECTS. tissue per minute, was calculated from the change in forearm circumference during venous occlusion in the manner described by Whitney (9) and modified by Holling and colleagues (13). Forearm vascular resistance was calculated as the ratio of mean arterial pressure to forearm blood flow and was expressed in units of $\mathrm{mm} \mathrm{Hg}$ per $\mathrm{ml}$ per $100 \mathrm{~g}$ per minute. The pressurevolume characteristics of the capacitance vessels, expressed in units of $\mathrm{mm} \mathrm{Hg}$ per $\mathrm{ml}$, were calculated by determining the ratio of the increment in venous pressure to the increment in forearm volume that occurred after inflation of the venous occlusion cuff. Venous pressure and volume were measured 10 seconds after the venous occlusion (Figure 1). Since both pressure and volume rose in an almost linear fashion immediately after occlusion, this ratio was not altered significantly by the precise time during the first 30 seconds after occlusion when the measurements were made. This ratio has also been used by Sharpey-Schafer to express the pressurevolume characteristics of the venous bed (16), and it is analogous to the initial slope of the curve relating venous pressure to volume utilized by Gauer and Thron (17). All measurements were carried out with the subjects in the supine position in a room maintained at a constant temperature of $24^{\circ} \mathrm{C}$.

Two venous catheters were employed in 2 normal subjects and in 1 patient with congestive heart failure. One catheter was introduced into a vein on the ulnar and the other into a vein on the radial aspect of the wrist. No observable differences were noted in venous tone calculated from the increment in venous pressure that occurred in either vein, before or after ouabain administration (Figure 2). 
TABLE II

in 12 normal subjects*

\begin{tabular}{|c|c|c|c|c|c|c|c|c|c|}
\hline \multicolumn{2}{|c|}{ HR } & \multicolumn{2}{|c|}{$\mathrm{CI}$} & \multicolumn{2}{|c|}{$\mathrm{FBF} / \mathrm{CO}$} & \multicolumn{2}{|c|}{ CVP } & \multicolumn{2}{|c|}{ SVR } \\
\hline $\mathrm{C}$ & 0 & $\mathrm{C}$ & $\mathrm{O}$ & $\mathrm{C}$ & 0 & $\mathrm{C}$ & 0 & C & 0 \\
\hline \multicolumn{2}{|c|}{ beats/min } & \multicolumn{2}{|c|}{$L / \min / m^{2}$} & \multicolumn{2}{|c|}{$\mathrm{ml} / 100 \mathrm{~g} / \mathrm{min}$} & \multicolumn{2}{|c|}{$m m \mathrm{Hg}$} & \multicolumn{2}{|c|}{ dyne-sec-cm-s } \\
\hline $\begin{array}{l}70 \\
69 \\
69 \\
65 \\
68 \\
69\end{array}$ & $\begin{array}{l}70 \\
67 \\
59 \\
58 \\
68 \\
59\end{array}$ & & & & & $\begin{array}{l}5.8 \\
6.4 \\
7.3 \\
6.0 \\
4.0 \\
8.7\end{array}$ & $\begin{array}{l}5.6 \\
6.0 \\
7.8 \\
6.0 \\
3.8 \\
8.3\end{array}$ & & \\
\hline 79 & 71 & 3.83 & 3.61 & 0.27 & 0.21 & 6.3 & 6.7 & 952 & 1,036 \\
\hline 60 & 53 & 3.12 & 2.94 & 0.19 & 0.15 & 8.3 & 9.4 & 1,180 & 1,600 \\
\hline 54 & 51 & 3.20 & 3.03 & 0.25 & 0.21 & 5.2 & 6.4 & 1,071 & 1,432 \\
\hline 71 & 63 & 3.38 & 3.33 & 0.45 & 0.41 & 4.4 & 5.4 & 845 & 880 \\
\hline 68 & 60 & 3.17 & 3.11 & 0.29 & 0.28 & 3.7 & 4.2 & 1,122 & 1,330 \\
\hline 85 & 78 & 3.47 & 3.53 & 0.22 & 0.19 & 1.4 & 1.1 & 1,343 & 1,347 \\
\hline 69 & 63 & 3.36 & 3.26 & 0.28 & 0.24 & 5.6 & 5.9 & 1,086 & 1,271 \\
\hline 2.28 & 2.27 & 0.12 & 0.11 & 0.041 & 0.042 & 0.52 & 0.64 & 73 & 108 \\
\hline \multicolumn{2}{|c|}{$<0.05$} & \multicolumn{2}{|c|}{$>0.05$} & \multicolumn{2}{|c|}{$<0.01$} & \multicolumn{2}{|c|}{$>0.1$} & \multicolumn{2}{|c|}{$<0.05$} \\
\hline
\end{tabular}

In 1 normal subject the venous occluding cuff was suddenly inflated to $30 \mathrm{~mm} \mathrm{Hg}$, and venous pressure and forearm circumference were permitted to equilibrate for 2 minutes. In this subject venous tone was calculated by the increments in volume and pressure that had taken place after the full 2-minute period. In 1 normal subject and in 1 patient with congestive heart failure, the effects of digitalis on venous tone were assessed by a modification of the stepwise venous occlusion method described by Wood and Eckstein (15). The forearm was elevated so that the venous pressure fell to zero, the wrist cuff was inflated to suprasystolic levels, and the venous occluding cuff was inflated in $5-\mathrm{mm} \mathrm{Hg}$ increments to $30 \mathrm{~mm} \mathrm{Hg}$. Sufficient time was permitted to elapse between these stepwise inflations for the venous pressure and forearm circumference to reach stable values.

In 6 of the 12 normal subjects and in 4 of the 6 patients with heart failure, cardiac output was determined during the control period and at 60 minutes after the infusion of ouabain by the dye dilution method, the technique and reliability of which have been described elsewhere (18). Indocyanine dye was injected through a $\mathrm{PE}$ no. 50 catheter placed in the superior vena cava through an antecubital vein of the forearm opposite the one from which the venous occlusion curves were obtained. In these patients measurements of central venous pressure were obtained at 5-minute intervals during the control period and at 5-minute intervals for the 60 minutes after the infusion of ouabain.

All studies were performed with the patient in the basal, postabsorptive state. After placement of the catheters and needles, 15 minutes was permitted to elapse for the patient to reach a stable state. Four control venous occlusion curves were obtained at 5-minute intervals by the acute inflation method to determine forearm blood flow and forearm venous tone. Ouabain, 0.50 $\mathrm{mg}$ to $0.60 \mathrm{mg}$, representing doses ranging between 0.0069 $\mathrm{mg}$ per $\mathrm{kg}$ and $0.016 \mathrm{mg}$ per $\mathrm{kg}$ (average, $0.0085 \mathrm{mg}$ per $\mathrm{kg}$ ), was then infused through a vein in the opposite forearm over a 10-minute period. Venous occlusion curves were recorded at 5-minute intervals for the next 60 minutes. In the subject whose venous tone was measured by the method in which venous occlusion was maintained for 2 minutes, and in the patients whose venous tone was determined by the method of stepwise venous occlusion, four measurements were made at 5-minute intervals during the control period and repeated at $15-\mathrm{min}-$ ute intervals for the 60 minutes after the infusion of ouabain.

In 4 of the normal subjects, the effects of ouabain were studied during the control state and after adrenergic blockade had been induced by the administration of guanethidine. The latter drug was administered orally with maximal doses ranging from 30 to $50 \mathrm{mg}$ per day for 5 weeks, and at the time of the second study, adrenergic blockade had been achieved as evidenced by postural hypotension, abolition of the post-Valsalva arterial pressure overshoot, and the absence of an increase in forearm vascular resistance and venous tone during the cold pressor test (19).

In addition, control studies were carried out in 6 normal subjects and in 3 patients with congestive heart failure. Measurements of arterial pressure, forearm blood flow, venous tone by the acute occlusion method, heart rate, and central venous pressure were made before and after a 40-minute control period. These studies were otherwise identical to those in which ouabain was given.

\section{Results}

\section{Control studies}

The measurements carried out before and after a 40-minute control period are presented in Table 

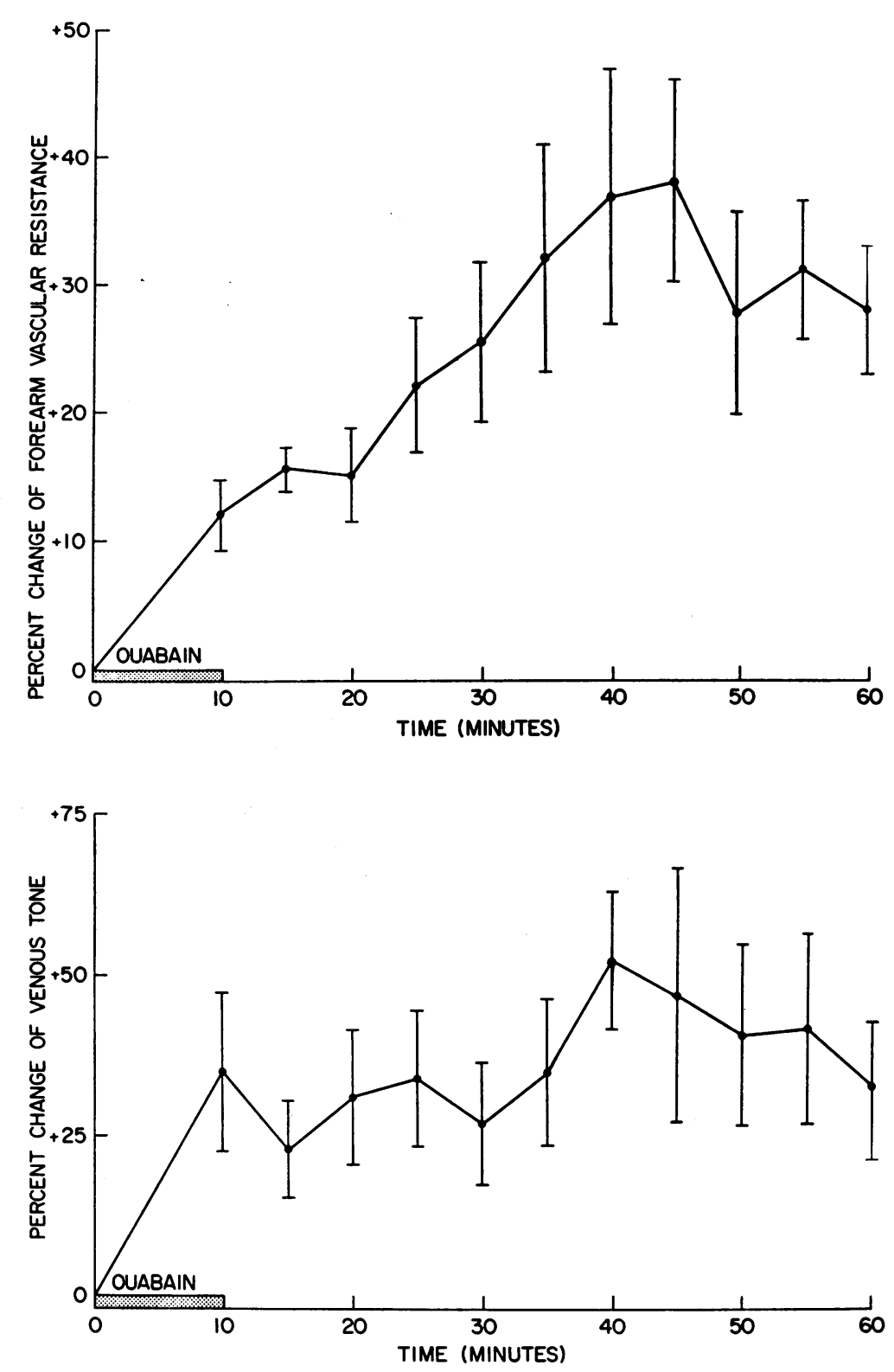

Fig. 3. Average change ( \pm SEM) of Forearm vascular Resistance (top) AND FOREARM VENOUS TONE (bottom) EXPRESSED AS PERCENTAGE OF CHANGES FROM THE CONTROL VALUES IN THE NORMAL SUBJECTS.

I. Since there were no consistent directional changes in any variable either in the normal subjects or the patients in heart failure, the data for all 9 individuals are presented together. Although there was considerable variation in the individual values among the 9 patients, the relative changes occurring in any given patient during the 40-minute period were small, and the changes for the group as a whole were not statistically significant, with $\mathrm{p}$ values greater than 0.5 for each variable. The average values of each variable measured before and after the 40 -minute waiting period were almost identical.

\section{Normal subjects}

Acute occlusion technique. Table II shows the values for mean arterial pressure, forearm blood flow, forearm vascular resistance, and forearm 


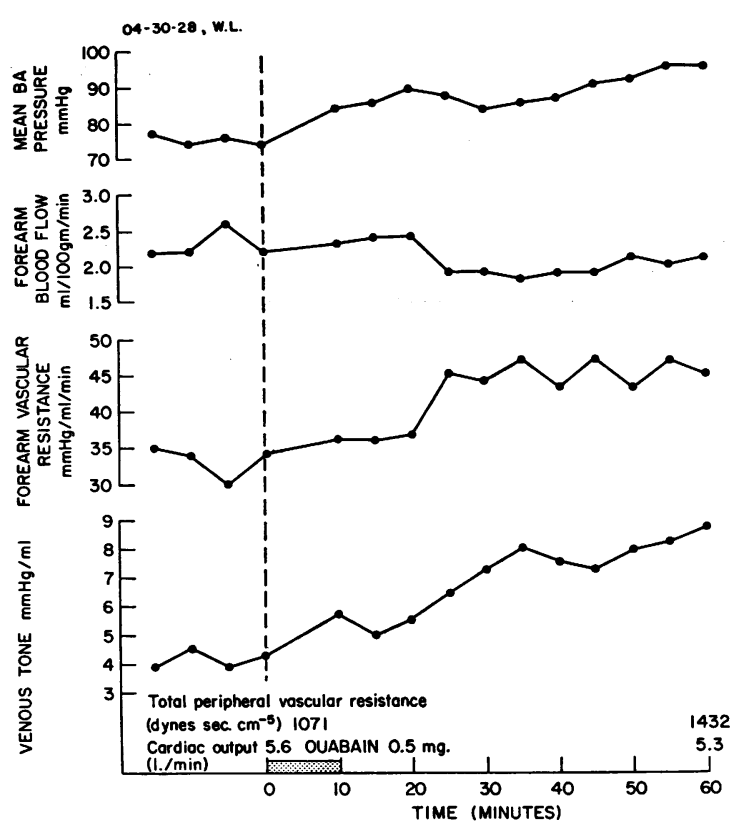

Fig. 4. Serial determinations of ARTERIAl PRESSURE (BA), FOREARM BLOOD FLOW, FOREARM VASCULAR RESISTANCE, VENOUS TONE, CARDIAC OUTPUT, AND SYSTEMIC VASCULAR RESISTANCE BEFORE AND AFTER OUABAIN IN A NORMAL SUBJECT.

venous tone during the control period and 40 minutes after the onset of the ouabain infusion in the 12 normal subjects in whom the effects of this drug were studied by the acute occlusion techniques. The time course of the effects of ouabain on mean systemic arterial pressure, forearm blood flow, forearm vascular resistance and venous tone, expressed as percentages of changes from the control, are shown in Figures 2 and 3. After the administration of the drug, mean arterial pressure rose significantly $(p<0.01)$, while forearm blood flow declined significantly $(\mathrm{p}<0.01)$. As a consequence, calculated forearm vascular resistance rose significantly $(p<0.01)$. Venous tone, which was determined in 10 of the 12 subjects, also rose significantly $(\mathrm{p}<0.01)$.

Cardiac output was determined before and 60 minutes after ouabain infusion in 6 of these 12 subjects. During the control period the cardiac index averaged $3.36 \pm 0.12(\mathrm{SEM}) \mathrm{L}$ per minute per $\mathrm{m}^{2}$, and after ouabain it averaged $3.26 \pm 0.11$ $\mathrm{L}$ per minute per $\mathrm{m}^{2}$. The change was not statistically significant $(p>0.05)$. Calculated systemic vascular resistance averaged 1,068 \pm 69 dyne-sec$\mathrm{cm}^{-5}$ before ouabain and rose in all 6 subjects to an average value of $1,271 \pm 108$ dyne-sec-cm ${ }^{-5}$. The elevation of systemic vascular resistance was statistically significant $(p<.05)$. Central venous pressure showed no consistent or significant change. Serial observations in 1 subject are reproduced in Figure 4.

Ouabain decreased the forearm blood flow proportionately more than the total cardiac output in each of the 6 subjects in whom both measurements were made. Before ouabain the ratio of forearm blood flow (in $\mathrm{ml}$ per $100 \mathrm{~g}$ per minute) to total cardiac output, also expressed as $\mathrm{ml}$ per $100 \mathrm{~g}$ body weight per minute, ranged between 0.19 and 0.45 , with an average of 0.28 . Sixty minutes after ouabain this ratio declined in every subject, ranging between 0.15 and 0.41 with an
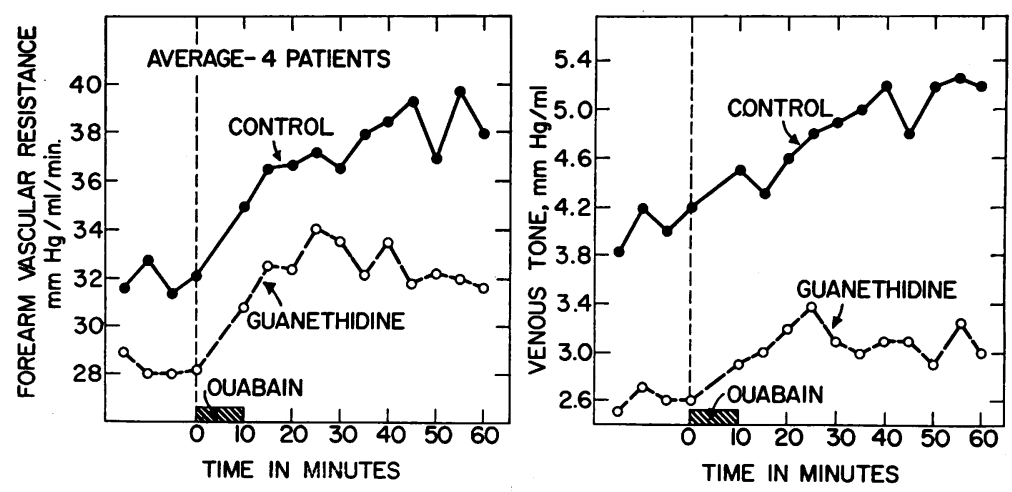

Fig. 5. Average values in 4 SUBJECts SHOWING the efFects of OUABain ON FOREARM VASCULAR RESISTANCE (left) AND VENOUS TONE (right) DURING A CONTROL PERIOD (solid dots, solid lines) AND AFTER GUANETHIDINE (open circles, broken lines). 
TABLE 111

Circulatory effects of ouabain

\begin{tabular}{|c|c|c|c|c|c|c|c|c|}
\hline \multirow[b]{2}{*}{ Patient } & \multicolumn{2}{|c|}{ MAP } & \multicolumn{2}{|c|}{ FBF } & \multicolumn{2}{|c|}{ FVR } & \multicolumn{2}{|c|}{ VT } \\
\hline & C & 0 & C & 0 & C & o & C & o \\
\hline & \multicolumn{2}{|c|}{$m m \mathrm{Hg}$} & \multicolumn{2}{|c|}{$m l / 100 \mathrm{~g} / m \imath n$} & \multicolumn{2}{|c|}{$\frac{m m H g}{m l / 100 \mathrm{~g} / \min }$} & \multicolumn{2}{|c|}{$m m H g / m b$} \\
\hline $\begin{array}{l}\text { A.L. } \\
\text { ASCVD, NSR }\end{array}$ & 71 & 70 & 2.65 & 3.05 & 26.8 & 22.9 & 21.8 & 16.1 \\
\hline $\begin{array}{l}\text { M.K. } \\
\text { RHD, AF }\end{array}$ & 79 & 78 & 1.15 & 1.40 & 68.6 & 55.7 & 24.1 & 19.0 \\
\hline $\begin{array}{l}\text { C.C. } \\
\text { RHD, AF }\end{array}$ & 88 & 88 & 1.57 & 1.83 & 56.0 & 48.1 & 4.4 & 2.2 \\
\hline $\begin{array}{l}\text { L.V. } \\
\text { ASCVD, AF }\end{array}$ & 81 & 84 & 1.80 & 3.12 & 45.0 & 26.9 & 3.0 & 1.6 \\
\hline $\begin{array}{l}\text { B.R. } \\
\text { RHD, AF }\end{array}$ & 83 & 81 & 1.68 & 1.85 & 49.4 & 43.8 & 5.5 & 4.5 \\
\hline $\begin{array}{l}\text { B.H. } \\
\text { RHD, AF }\end{array}$ & 79 & 73 & 1.18 & 1.70 & 67.0 & 42.9 & 21.1 & 12.3 \\
\hline \multirow[t]{2}{*}{$\begin{array}{l}\text { Average } \\
\pm \text { SEM }\end{array}$} & $\begin{array}{l}80 \\
2.26\end{array}$ & $\begin{array}{l}79 \\
3.09\end{array}$ & $\begin{array}{l}1.67 \\
0.15\end{array}$ & $\begin{array}{l}2.16 \\
0.30\end{array}$ & $\begin{array}{r}52.1 \\
6.3\end{array}$ & $\begin{array}{r}40.1 \\
5.1\end{array}$ & $\begin{array}{r}13.3 \\
4.0\end{array}$ & $\begin{array}{r}9.3 \\
-\quad 3.0\end{array}$ \\
\hline & \multicolumn{2}{|c|}{$>0.3$} & \multicolumn{2}{|c|}{$<0.05$} & \multicolumn{2}{|c|}{$<0.02$} & \multicolumn{2}{|c|}{$<0.05$} \\
\hline
\end{tabular}

* Abbreviations and times of measurement same as in Table II.

average of 0.24 . The change in the ratio was statistically significant $(\mathrm{p}<.01)$.

Acute occlusion technique after guanethidine. In 4 of the 12 subjects studied by the acute occlusion technique, the effects of ouabain were determined before and after 5 weeks of treatment with guanethidine. During the control state, i.e., before the administration of ouabain, guanethidine administration lowered the values for forearm vascular resistance in all 4 subjects and venous tone in 3 of the 4 subjects. The average extent of the elevation of these two variables produced by ouabain was, however, essentially the same before and after guanethidine (Figure 5 ).

Equilibration techniques. The effects of ouabain on venous tone, determined by measuring forearm venous pressure and circumference 2 minutes after inflating the occlusion cuff to $30 \mathrm{~mm} \mathrm{Hg}$, are shown in Figure 6A. As observed with the acute occlusion technique, an
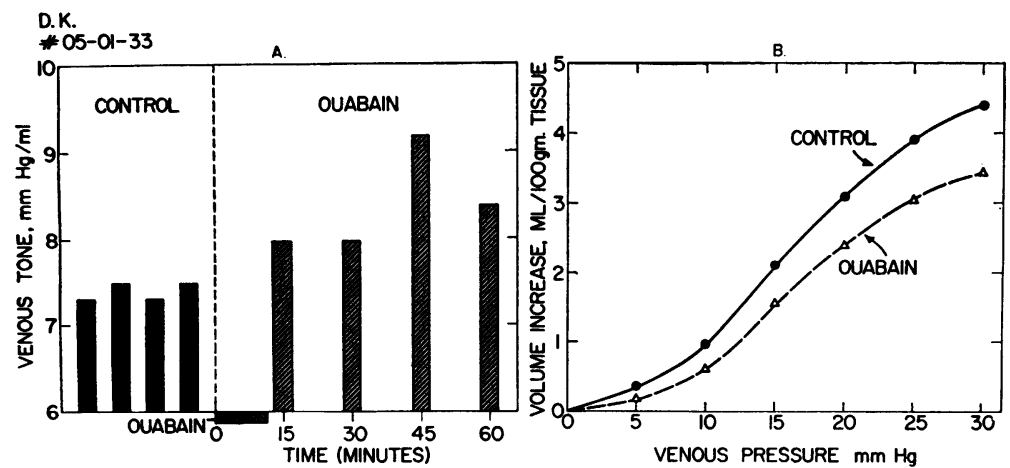

Fig. 6. A. Venous tone measurements CARried out 2 minutes AFter INFLATION OF THE OCCLUSION CUFF. The four black bars represent four values during the control period. The cross-hatched bars represent measurements made after ouabain.

B. Relationship Between venous PRESSURe AND FOREARM VOLUME INCREASE, DETERMINED BY THE STEPWISE OCCLUSION METHOD, DURING THE CONTROL PERIOD AND AFTER OUABAIN. 
TABLE III

in 6 patients in heart failure*

\begin{tabular}{|c|c|c|c|c|c|c|c|c|c|}
\hline \multicolumn{2}{|c|}{ HR } & \multicolumn{2}{|c|}{ CI } & \multicolumn{2}{|c|}{$\mathrm{FBF} / \mathrm{CO}$} & \multicolumn{2}{|c|}{ CVP } & \multicolumn{2}{|c|}{ SVR } \\
\hline C & o & $\mathrm{C}$ & $\mathbf{O}$ & $\mathrm{C}$ & $\mathbf{0}$ & $\mathbf{C}$ & o & C & $\mathbf{O}$ \\
\hline \multicolumn{2}{|c|}{ beats/min } & \multicolumn{2}{|c|}{$L / \mathrm{min} / \mathrm{m}^{2}$} & \multicolumn{2}{|c|}{$\mathrm{ml} / 100 \mathrm{~g} / \mathrm{min}$} & \multicolumn{2}{|c|}{$m m H_{g}$} & \multicolumn{2}{|c|}{ dyne-sec-cm-s } \\
\hline 86 & 74 & & & & & 12.3 & 10.8 & & \\
\hline 136 & 114 & 2.11 & 3.41 & 0.17 & 0.13 & 16.8 & 13.7 & 2,375 & 1,252 \\
\hline 109 & 72 & 1.76 & 2.91 & 0.35 & 0.24 & 11.6 & 9.6 & 2,125 & 1,310 \\
\hline 120 & 104 & & & & & 13.7 & 12.7 & & \\
\hline 105 & 90 & 1.70 & 2.37 & 0.38 & 0.31 & 14.0 & 12.7 & 2,020 & 1,610 \\
\hline 89 & 69 & 1.15 & 2.18 & 0.34 & 0.26 & 17.0 & 11.4 & 3,430 & 1,461 \\
\hline $\begin{array}{l}108 \\
7.65\end{array}$ & $\begin{array}{l}87 \\
7.18\end{array}$ & $\begin{array}{l}1.68 \\
0.20\end{array}$ & $\begin{array}{l}2.72 \\
0.30\end{array}$ & $\begin{array}{l}0.31 \\
0.039\end{array}$ & $\begin{array}{l}0.24 \\
0.031\end{array}$ & $\begin{array}{c}14.2 \\
0.91\end{array}$ & $\begin{array}{c}11.8 \\
0.61\end{array}$ & $\begin{array}{r}2,488 \\
323\end{array}$ & $\begin{array}{r}1,408 \\
81\end{array}$ \\
\hline \multicolumn{2}{|c|}{$<0.01$} & \multicolumn{2}{|c|}{$<0.01$} & \multicolumn{2}{|c|}{$<0.02^{0.031}$} & \multicolumn{2}{|c|}{${ }^{0.91}<0.02$} & \multicolumn{2}{|c|}{$<0.05$} \\
\hline
\end{tabular}

increase in venous tone occurred. The effects of ouabain on the venous pressure-volume curve, determined in the same subject by the stepwise occlusion method, are shown in Figure 6B. At any given venous pressure, the increment in forearm volume was less after ouabain than before, signifying that an increase in venous tone, i.e., venoconstriction, has taken place (15).

\section{Patients in congestive heart failure}

Acute occlusion technique. The effects of ouabain were studied by the acute occlusion technique in 6 patients in congestive heart failure; the results are summarized in Table III. The maximal changes in forearm blood flow, vascular resistance, and venous tone usually occurred between 30 and 50 minutes after the beginning of the infusion, and the observations carried out in each subject 40 minutes after ouabain are presented.

Before the administration of ouabain, the forearm blood flow was significantly lower $(p<.01)$ and the forearm vascular resistance significantly greater $(p<.01)$ in the patients with heart failure than in the normal subjects. Forearm venous tone was also significantly greater $(p<.05)$ in the patients with heart failure than in the normal subjects.

The effects of ouabain in the patients with heart failure differed markedly from those observed in

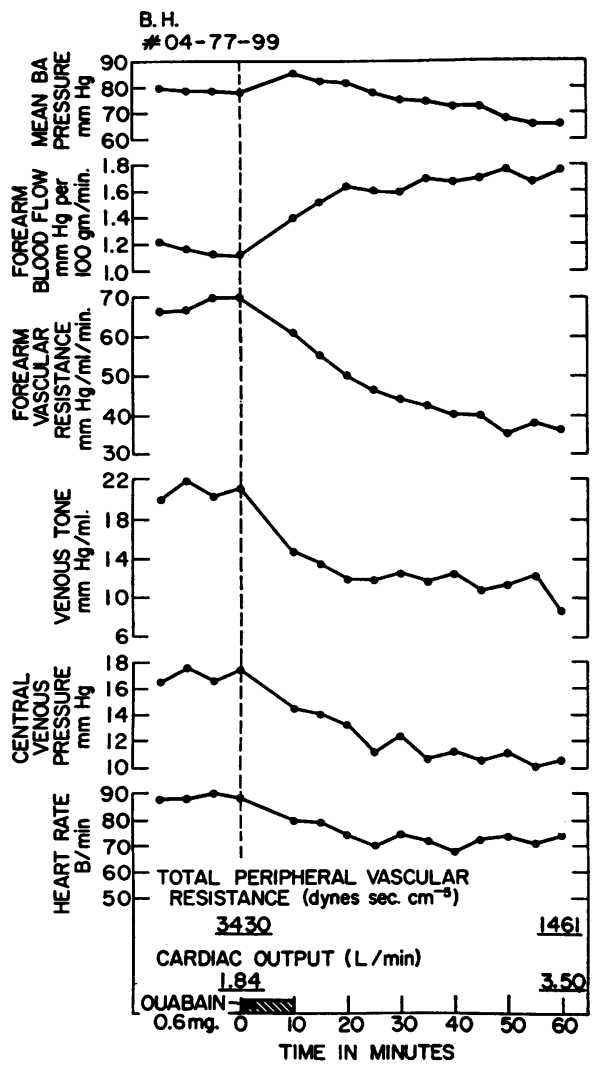

Fig. 7. Serial measurements before and AFter ouaBAIN IN PATIENT B.H. WITH CONGESTIVE HEART FAILLRE. 


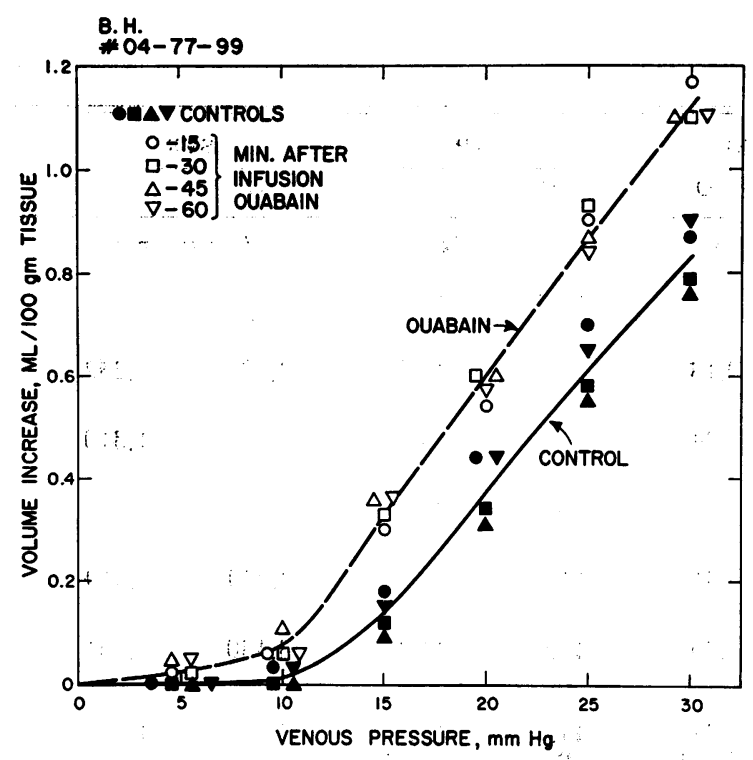

Fig. 8. Relationship betWeEN venous PRESSURE AND FOREARM VOLUME INCREASE, DETERMINED BY THE STEPWISE OCCLUSION METHOD, DURING FOUR CONTROL MEASUREMENTS AND AT 15-MINUTE INTERVALS AFTER OUABAIN IN B.H. (whose data is also presented in Figure 7).

the normal subjects. There was no significant effect on mean arterial pressure. After the glycoside, however, forearm blood flow and cardiac output rose, whereas forearm venous tone, forearm vascular resistance, heart rate, central venous pressure, and systemic vascular resistance declined significantly (Table III). In the 4 patients in whom the ratio of forearm blood flow to total cardiac output was measured, it averaged 0.31 and ranged between 0.17 and 0.38 before ouabain. It declined in each patient after the drug, ranging between 0.13 and 0.31 and averaging 0.24 . This decline was also significant statistically $(\mathrm{p}<.02)$. Serial observations in 1 patient (B.H.) are reproduced in Figure 7.

Equilibration technique. The effects of ouabain on the venous pressure-volume curve, determined in one patient by the stepwise occlusion method, are shown in Figure 8. The four control observations showed little variation. However, in all four observations after ouabain, at any given venous pressure the increment in forearm volume was greater after ouabain than before, signifying that a decrease in venous tone, i.e., venodilatation, had occurred.

\section{Discussion}

In the normal subjects the administration of ouabain in the usual clinical doses resulted in an increase in systemic arterial pressure and simultaneously in a decline in forearm blood flow, indicating that the drug resulted in constriction of the resistance vessels of the forearm. The ratio of the rise of forearm venous pressure to forearm volume during sudden venous occlusion also increased after ouabain, suggesting that constriction of the capacitance vessels had occurred as well. The increase in this ratio resulted from a more rapid rise in venous pressure and a less rapid rise in forearm volume after ouabain than during the control period (Figure 1). Any given percentage of change in venous tone, as measured by the acute occlusion method, does not reflect an identical percentage of change in the tension of the smooth muscle of the veins. However, the interpretation that venoconstriction had occurred is further substantiated by the findings in the subject in whom forearm venous tone was estimated by the stepwise inflation method and by the technique in which forearm pressure and volume were measured 2 minutes after inflation (Figure 6). Furthermore, preliminary observations by Horsley and Eckstein indicated that acetylstrophanthidin resulted in mild venous constriction in 5 subjects, without a detectable effect in 4 others (20). The absence of any significant or consistent changes in forearm venous tone during a 40-minute period in which no drug was given adds confidence to the conclusion that the consistent changes observed after ouabain were indeed induced by this drug. However, the acute effects of ouabain are not necessarily those of all digitalis preparations used chronically.

Since the changes in the resistance and capacitance vessels produced by ouabain occurred in the face of a stable cardiac output and an elevation of systemic arterial pressure, the effect of the drug is probably a direct one on the vascular smooth muscle. The constriction of the vascular beds could not have resulted from reflexes mediated through the baroreceptor reflex arc, since the elevation of mean arterial pressure that occurred might be expected to result in an inhibition, rather than an augmentation, of both arteriolar and venous tone (21). That ouabain has a direct con- 
stricting effect on vascular smooth muscle is also supported by the finding in the 4 subjects who were studied both before and after prolonged treatment with the adrenergic blocking drug, guanethidine. In these subjects the reflex arteriolar and venous constriction that occurs during the cold pressor test had been abolished, yet ouabain still resulted in an increase of forearm vascular resistance and venous tone (Figure 5 ).

Although previous studies on isolated vascular strips $(1-4)$, on the perfused hind limb of the $\operatorname{dog}(5,22)$, and on the total systemic circulation of dogs, sheep, and humans on cardiopulmonary bypass $(5,6,8,23)$ indicate that digitalis glycosides constrict vascular smooth muscle, the conditions under which these experiments were carried out were grossly abnormal, and the relevance of the data to intact, unanesthetized, normal man may be questioned. The present investigation thus extends the concept of glycoside-induced arteriolar and venoconstriction to the vessels of the forearm of normal, unanesthetized man. Since ouabain resulted in a fall in forearm blood flow while total cardiac output was essentially unchanged, the ratio of forearm blood flow to total cardiac output declined. If the changes in the forearm are considered to be representative of those occurring in skeletal muscle in other parts of the body, this finding suggests that a significant redistribution of the cardiac output had taken place, and that blood flow in regions other than the skeletal muscle may have increased.

In the patients with congestive heart failure before the administration of ouabain, the forearm blood flow was lower, and the calculated forearm vascular resistance and venous tone were greater than in the normal subjects. These findings agree with those of previous investigators (24-28). The effects of ouabain in these patients differed strikingly from those observed in the normal subjects. In all 6 patients with heart failure, the glycoside augmented forearm blood flow, while mean arterial pressure remained essentially stable. Therefore, forearm vascular resistance declined. Venous tone, calculated by the acute occlusion technique, decreased in every patient with congestive heart failure after ouabain, a finding also confirmed by the observations in the patient studied by the stepwise occlusion method (Figure 8). Again in contrast to the normal subjects, ouabain resulted in a marked rise in cardiac index and a decline in heart rate, central venous pressure, and calculated systemic vascular resistance (Table II). The latter findings are consonant with those observed by other investigators who have studied the effects of glycosides on the circulatory dynamics of patients with congestive heart failure (24).

The effect of the glycoside on the vascular dynamics of the forearm is, therefore, apparently dependent on the circulatory state of the patient at the time the drug is administered. However, the reason for the opposite effects of ouabain on the forearm vascular resistance and venous tone of the two groups of patients studied has not yet been completely elucidated. Some investigators have postulated that the peripheral vasoconstriction in patients with congestive heart failure results from increased activity of the sympathetic nervous system (29), a view supported by the finding that the vasoconstriction has been diminished by ganglionic blockade $(30,31)$. The elevation of cardiac output induced by ouabain in patients with heart failure may result in a diminution of the adrenergically induced arteriolar and venoconstriction in the forearm. Our observations and this interpretation are in agreement with the studies of Wood, Litter, and Wilkins, who noted that the constriction of the forearm veins in patients with heart failure diminishes as the state of cardiac compensation improves (25). We are also in agreement with Wood that a given level of muscular exercise results in forearm venoconstriction in patients with heart failure but does not induce venoconstriction in patients with compensated heart disease (27). Thus, we postulate that as a consequence of the improvement in cardiac dynamics induced by ouabain in the patients with heart failure, the state of the resistance and capacitance vessels in their forearms changes towards normal. In the patients with congestive heart failure, this inhibition of vasoconstriction appears to override the direct vasoconstrictive action of the drug on vascular smooth muscle, observed consistently in the normal individuals.

The finding that digitalization results in systemic venodilatation in patients in congestive heart failure provides an explanation for the clinical observation that rapid digitalization of patients in heart failure may result in a fall in the systemic 
venous pressure before the onset of diuresis. Our observations are also consonant with those of McMichael and Sharpey-Schafer (32), who suggested that relaxation of the veins might be the primary action of digitalis and that the elevation of the cardiac ouput in patients with heart failure is secondary to venous pooling. Subsequent work from the same laboratory did not, however, substantiate this hypothesis $(33-35)$. The present investigation agrees with the idea that in patients with heart failure digitalis glycosides result in venodilatation, as McMichael and Sharpey-Schafer originally suggested (32), but this venodilatation is probably an indirect effect. Our observations on venous tone are also consonant with the findings of Bradley $(36,37)$, who noted that the elevation of cardiac output and fall in central venous pressure induced by digoxin in patients with congestive heart failure is associated with a decline of the splanchnic blood volume. Bradley inferred that digitalis results in the elimination of widespread venoconstriction, an action that results in the displacement of blood from the splanchnic vascular bed to the systemic veins and venules (36). Our data support this view.

\section{Summary}

The effects of intravenous injection of ouabain on the vascular dynamics of the forearm were studied in 12 normal subjects and in 6 patients with congestive heart failure. In the normal group, the cardiac glycoside resulted in a fall in forearm blood flow and an elevation of calculated forearm vascular resistance and venous tone. A similar effect was observed in 4 subjects who were pretreated with an adrenergic blocking agent. From these observations we conclude that in therapeutic doses ouabain has a direct constricting action on the vascular smooth muscle of the forearm of normal human subjects.

In the patients with congestive heart failure the glycoside tended to restore the hemodynamic abnormalities in the forearm towards normal. Thus, it elevated forearm blood flow and lowered the elevated forearm vascular resistance and venous tone. We suggest that these effects are indirect, resulting from the improvement of the congestive heart failure state by the drug, and we postulate that this improvement diminished reflex arteriolar and venoconstriction in the patients with heart failure.

\section{References}

1. Cow, D. Some reactions of surviving arteries. J. Physiol. 1911, 42, 125.

2. Franklin, K. J. The pharmacology of the isolated vein ring. J. Pharmacol. exp, Ther. 1925, 26, 215.

3. Leonard, E. Alteration of contractile response of artery strips by a potassium-free solution, cardiac glycosides, and changes in stimulation frequency. Amer. J. Physiol. 1957, 189, 185.

4. Lendle, L., and H. Mercker. Extrakardiale Digitaliswirkungen. Ergebn. Physiol. 1961, 51, 199.

5. Ross, J., Jr., J. A. Waldhausen, and E. Braunwald. Studies on digitalis. I. Direct effects on peripheral vascular resistance. J. clin. Invest. 1960, 39, 930.

6. Ross, J., Jr., E. Braunwald, and J. A. Waldhausen. Studies on digitalis. II. Extracardiac effects on venous return and on the capacity of the peripheral vascular bed. J. clin. Invest. 1960, 39, 937.

7. Williams, M. H., Jr., L. R. Zohman, and A. C. Ratner. Hemodynamic effects of cardiac glycosides on normal human subjects during rest and exercise. J. appl. Physiol. 1958, 13, 417.

8. Braunwald, E., R. D. Bloodwell, L. I. Goldberg, and A. G. Morrow. Studies on digitalis. IV. Observations in man on the effects of digitalis preparations on the contractility of the non-failing heart and on total vascular resistance. J. clin. Invest. 1961, 40, 52.

9. Whitney, R. J. The measurement of volume changes in human limbs. J. Physiol. 1953, 121, 1.

10. Clarke, R. S. J., and R. F. Hellon. Venous collection in forearm and hand measured by the straingauge and volume plethysmograph. Clin. Sci. -1957, 16, 103.

11. Horeman, H. W. Comparison of methods for measuring peripheral blood flow. Thesis, University of Utrecht, 1958, p. 102.

12. Burger, H. C., H. W. Horeman, and A. J. M. Brakkee. Comparison of some methods for measuring peripheral blood flow. Phys. in Med. Biol. 1959, 4, 168.

13. Holling, H. E., H. C. Boland, and E. Russ. Investigation of arterial obstruction using a mercuryin-rubber strain gauge. Amer. Heart J. 1961, 62, 194.

14. Mason, D. T., and E. Braunwald. A simplified plethysmographic system for the measurement of systemic arterial pressure and peripheral blood flow. Amer. Heart J. 1962, 64, 796.

15. Wood, J. E., and J. W. Eckstein. A tandem forearm plethysmograph for study of acute responses of the peripheral veins of man: The effect of environmental and local temperature change, and the effect of pooling blood in the extremities. $J$. clin. Invest. 1958, 37, 41. 
16. Sharpey-Schafer, E. P. Venous tone. Brit. med. J. 1961, 2, 1589.

17. Gauer, O. H., and H. L. Thron. Properties of veins in vivo: Integrated effects of their smooth muscle. Physiol. Rev. 1962, 42 (suppl. 5, part II), 283.

18. Chidsey, C. A., R. L. Frye, R. L. Kahler, and E. Braunwald. Influence of syrosingopine on the cardiovascular response to acute hypoxemia and exercise. Circulat. Res. 1961, 9, 989.

19. Mason, D. T., and E. Braunwald. Effects of antihypertensive drugs on reflex venoconstriction in man (abstract). Clin. Res. 1963, 11, 171.

20. Horsely, A. W., and J. W. Eckstein. The effect of acetyl strophanthidin on peripheral venous tone in man (abstract). J. Lab. clin. Med. 1959, 54, 827.

21. Ross, J., Jr., C. J. Frahm, and E. Braunwald. Influence of carotid baroreceptors and vasoactive drugs on systemic vascular volume and venous distensibility. Circulat. Res. 1961, 9, 75.

22. Bücherl, E., and M. Schwab. Der Einfluss von Strophanthin auf Gefässweite und Sauerstoffverbrauch des ruhenden Skeletmuskels. Klin. Wschr. 1952, $30,52$.

23. Tyrer, J. H. A comparison of the direct peripheral actions upon systemic venous pressure of $\mathrm{k}$-strophanthosid, digoxin and ouabain. Quart. J. exp. Physiol. 1953, 38, 117.

24. Goodman, L. S., and A. Gilman. The Pharmacological Basis of Therapeutics, 2nd ed. New York, Macmillan, 1955, p. 678.

25. Wood, J. E., J. Litter, and R. W. Wilkins. Peripheral venoconstriction in human congestive heart failure. Circulation 1956, 13, 524.

26. Burch, G. E. Evidence for increased venous tone in chronic congestive heart failure. Arch. intern. Med. 1956, 98, 750.
27. Wood, J. E. The mechanism of the increased venous pressure with exercise in congestive heart failure. J. clin. Invest. 1962, 41, 2020.

28. Donald, K. W., J. M. Bishop, and O. L. Wade. Changes in the oxygen content of axillary venous blood during leg exercise in patients with rheumatic heart disease. Clin. Sci. 1955, 14, 531.

29. Chidsey, C. A., D. C. Harrison, and E. Braunwald. Augmentation of the plasma norepinephrine response to exercise in patients with congestive heart failure. New Engl. J. Med. 1962, 267, 650.

30. Burch, R. R. The effects of intravenous hexamethonium on venous pressure of normotensive and hypertensive patients with and without congestive heart failure. Circulation 1955, 11, 271.

31. Kelley, R. T., E. D. Freis, and T. F. Higgins. The effects of hexamethonium on certain manifestations of congestive heart failure. Circulation 1953, 7, 169.

32. McMichael, J., and E. P. Sharpey-Schafer. The action of intravenous digoxin in man. Quart. J. Med. 1944, 13, 123.

33. Howarth, S., J. McMichael, and E. P. SharpeySchafer. Effects of venesection in low output heart failure. Clin. Sci. 1946, 6, 41.

34. Ahmed, S., R. I. S. Bayliss, W. A. Briscoe, and J. McMichael. The action of ouabain (g-strophanthin) on the circulation in man, and a comparison with digoxin. Clin. Sci. 1950, 9, 1.

35. McMichael, J. Dynamics of heart failure. Brit. med. J. 1952, 2, 578.

36. Bradley, S. E. Discussion of Green, H. D. Physiology of peripheral circulation in shock. Fed. Proc. 1961, 20, 61.

37. Bradley, S. E. The circulation and the liver. Gastroenterology 1963, 44, 403. 